\title{
Development of a mud transport model for the Scheldt estuary
}

\author{
Thijs VAN KESSEL ${ }^{1}$, Joris VANLEDE ${ }^{2}$, Johan DE KOK ${ }^{3}$ \\ 1. WL | Delft Hydraulics, P.O. Box 177, $2600 \mathrm{MH}$ Delft, The Netherlands. \\ Email: thijs.vankessel@wldelft.nl \\ 2. Flanders Hydraulics, Berchemlei 115, B-2140 Antwerpen, Belgium. \\ Email: joris.vanlede@mow.vlaanderen.be \\ 3. RIKZ, P.O. Box 20907, 2500 EX Den Haag, The Netherlands. \\ Email: johan.de.kok@rws.nl
}

Keywords: suspended sediment, 3D model, seasonal dynamics, Scheldt estuary.

\begin{abstract}
A mud transport model for the Scheldt estuary is being developed. It's purpose is to support managers of the Scheldt estuary with the solution of a number of managerial issues. The model domain ranges from the tidal boundary at Gent down to the Belgian coastal cities of Nieuwpoort and Zeebrugge.

The hydrodynamic simulations on that are used by the mud transport model show realistic values for water levels, salinities and residual currents in the major part of the model domain. However, the propagation of the tidal wave is modelled less accurately upstream of Antwerpen.

Regarding the mud transport simulations, the following is concluded:

1. Based on simple process formulations for mud transport, a satisfactory agreement is obtained between computed and observed concentration levels and their spatial and temporal variations.

2. The difference between simulations with 5 and 10 horizontal layers is only minor.

3. The SPM levels appear to be rather sensitive to the volume of harbour siltation and dumping.

4. The main issue requiring improvement is the unsatisfying sediment budget from the model. The model computes an unrealistically high residual sediment flux towards the North Sea (about 2 $\mathrm{MT} / \mathrm{y}$ ). If sediment dumping is in equilibrium with harbour siltation, this net export results in too low equilibrium SPM levels. This requires further attention.

5. A longer hydrodynamic simulation period (presently up to 3 month) would help to analyse the sediment budget and seasonal dynamics in more detail.
\end{abstract}

\section{Introduction}

The Scheldt estuary has many functions, such as providing a valuable habitat for estuarine nature and granting access to major seaports such as Antwerp and Vlissingen. The protection of the hinterland against flooding is a major concern. The management of the estuary asks for a continuous balancing of the aspects naturalness, accessibility and safety. The first two aspects are influenced by the mud dynamics of the Scheldt estuary, affecting the light climate, the bed composition of intertidal flats and the siltation in harbour basins. Therefore a mud transport model for the Scheldt estuary is being developed to support these management issues. This paper discusses the set-up, calibration and validation of this model. It contains the following elements. Firstly, a short overview is presented of the Scheldt estuary as a framework for the model development and evaluation. Secondly, field observations are presented, serving the same purpose. Subsequently, the model set-up, calibration and validation is discussed. Finally, conclusions are drawn.

\section{System description}

\subsection{Hydrodynamics and salinity}

The drainage basin of the Scheldt River covers an area of nearly $22,000 \mathrm{~km}^{2}$ and is situated in the north-east of France, the west of Belgium and the south-west of the Netherlands (Figure 1). The river is $350 \mathrm{~km}$ long and the water level difference between source and mouth is only $100 \mathrm{~m}$, making it a typical lowland river system with low current velocities and thus meanders. The Scheldt estuary extends $160 \mathrm{~km}$ in length and includes an approximately $60 \mathrm{~km}$ long fresh water tidal zone stretching from near the mouth of Rupel to Ghent, representing one of the Western Europe largest freshwater tidal areas. The Scheldt Estuary is open to the southern North Sea. At the 
Dutch side of the border, the estuary is named 'Western Scheldt' and can be divided into 6 estuarine sections, each consisting of a flood- and ebb channel, intertidal area and interconnecting channels.

The estuary has a semidiurnal meso- to macro-tidal regime. The tidal wave penetrates the estuary up to Gentbrugge (situated just downstream of Gent, $156 \mathrm{~km}$ from the mouth) where it is stopped by a sluice. The mean tidal range is $3.85 \mathrm{~m}$ at the mouth (Vlissingen) and increases up to $5.24 \mathrm{~m}$ at Schelle (1 km downstream of Rupelmonde, $91 \mathrm{~km}$ from the mouth). Further upstream it decreases to a value of $1.89 \mathrm{~m}$ at Gentbrugge $(156 \mathrm{~km})$. During spring tide (neap tide) the tidal range is 4.46 $\mathrm{m}(2.97 \mathrm{~m})$ at Vlissingen and $5.93 \mathrm{~m}(4.49 \mathrm{~m})$ at Schelle. The tidal wave first increases and decreases in upstream direction as it is affected by convergence, reflection and dissipation.

The time period between high water in the estuary (Terneuzen, Hansweert and Bath) and high water near Vlissingen has gradually decreased in history. In the $17^{\text {th }}$ century it was 5 hours, in 1900 2,5 hours, nowadays it is 2 hours. Since 1950 it has decreased with approximately another 10 minutes (i.e. 10 to $30 \%$ ). This decrease is due to land reclamation, decrease in tidal area and deepening of the navigation channels (Verlaan, 1998).

The high water levels increase (with $15 \mathrm{~cm}$ near Vlissingen and $25 \mathrm{~cm}$ near Bath and Antwerp) as well as the low water levels $(5 \mathrm{~cm}$ increase near Vlissingen, $10 \mathrm{~cm}$ and $25 \mathrm{~cm}$ decrease near Bath and Antwerp, respectively). Possibly the first deepening had a large impact on the water levels. The tidal range increased between 1900 and 1980 with $15 \mathrm{~cm}$ near Vlissingen and $35 \mathrm{~cm}$ near Bath. The largest increase took place during 1971 and 1980 (half of the mentioned values) (Verlaan, 1998).

Near the estuary mouth the tidal discharge has an annual average of $50,000 \mathrm{~m}^{3} / \mathrm{s}$ for both ebb and flood tides. More than $10^{9} \mathrm{~m}^{3}$ enters and leaves the estuary twice a day with the tide.

The river discharge varies from $50 \mathrm{~m}^{3} / \mathrm{s}$ during dry summer to $300 \mathrm{~m}^{3} / \mathrm{s}$ during wet winter. The annual average lies between 100 and $200 \mathrm{~m}^{3} / \mathrm{s}$, which is small compared to the tidal discharge. It is also small compared to the discharge of other European rivers (Rhine, $2200 \mathrm{~m}^{3} / \mathrm{s}$, Meuse $250 \mathrm{~m}^{3} / \mathrm{s}$ ). During a tidal cycle only $5 \times 10^{6} \mathrm{~m}^{3}$ of freshwater is discharged into the North Sea. $90 \%$ of the fluvial sediment is discharged in less than $10 \%$ of the time during high water discharges.

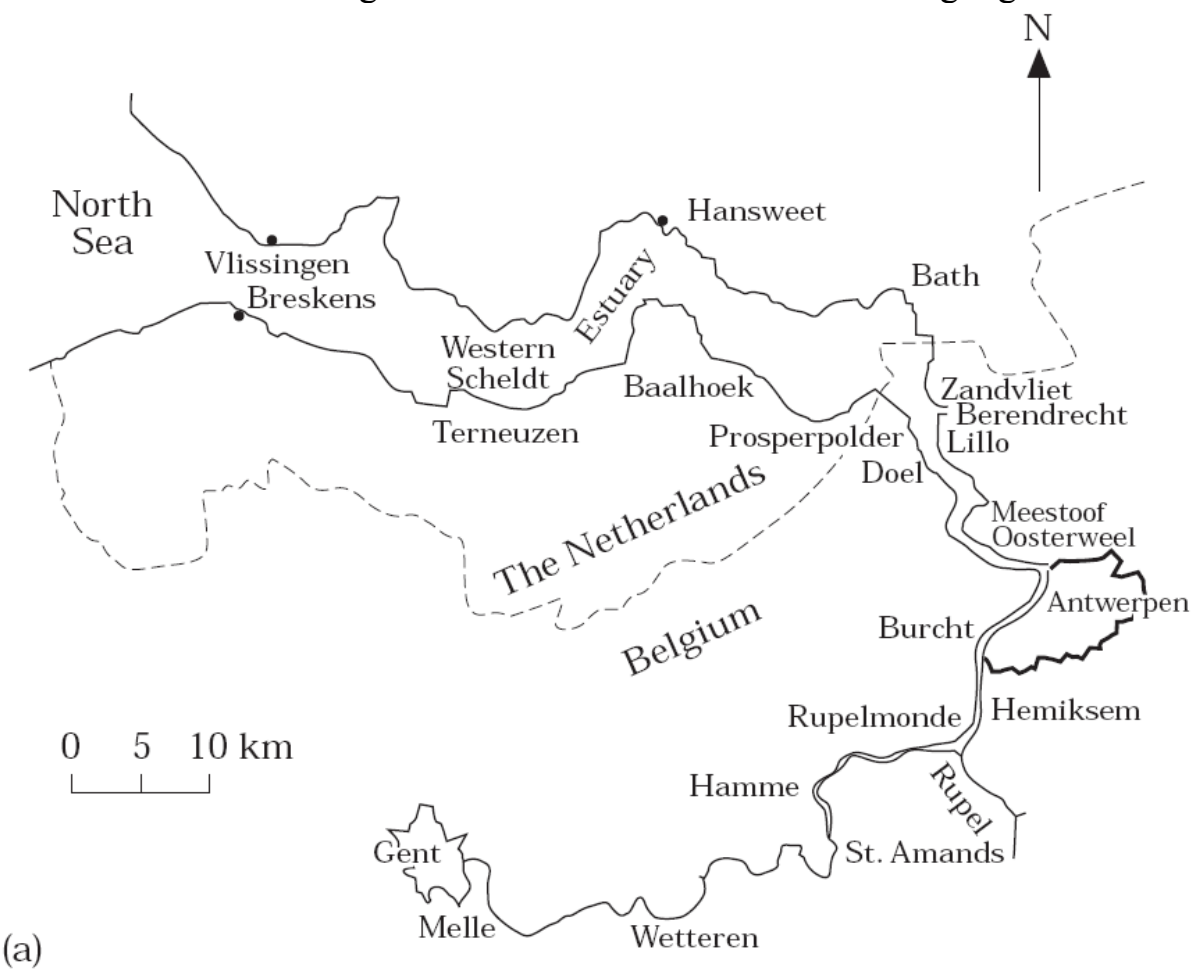

Figure 1: The Scheldt estuary (from Fettweis et al., 1998). 
Waves only influence the Western part near the mouth. Sediment transport is mainly determined by tidal flow, but waves have an effect on the morphology. Tides build intertidal areas, whereas waves break them down.

The salinity in the estuary varies from fresh water at Rupelmonde $(92 \mathrm{~km})$ to nearly the value of seawater at the mouth. During high discharge, sea water only penetrates to Antwerp, whereas during low discharge it penetrates farther than Rupelmonde. The zero salinity point can shift over a distance of about $40 \mathrm{~km}$. Figure 2 (from Verlaan 1998, after Claessens, 1988) shows the longitudinal salt distribution.

In the mixing zone (between Rupelmonde and Vlissingen) the vertical salinity difference is $1 \% 0$, in the partially mixed zone (between Antwerp and the Belgian/Dutch border) this difference is higher than upstream (homogeneous zone) and downstream. The difference is higher during spring $\left(4^{0} \%\right.$ ) than during neap tide $(2.8 \%$, averaged over a tidal cycle the difference is $1 \%$. Lateral differences are larger where a distinct separation between ebb and flood channels exist. The residence time of freshwater in the Scheldt estuary is estimated at $2-3$ months.

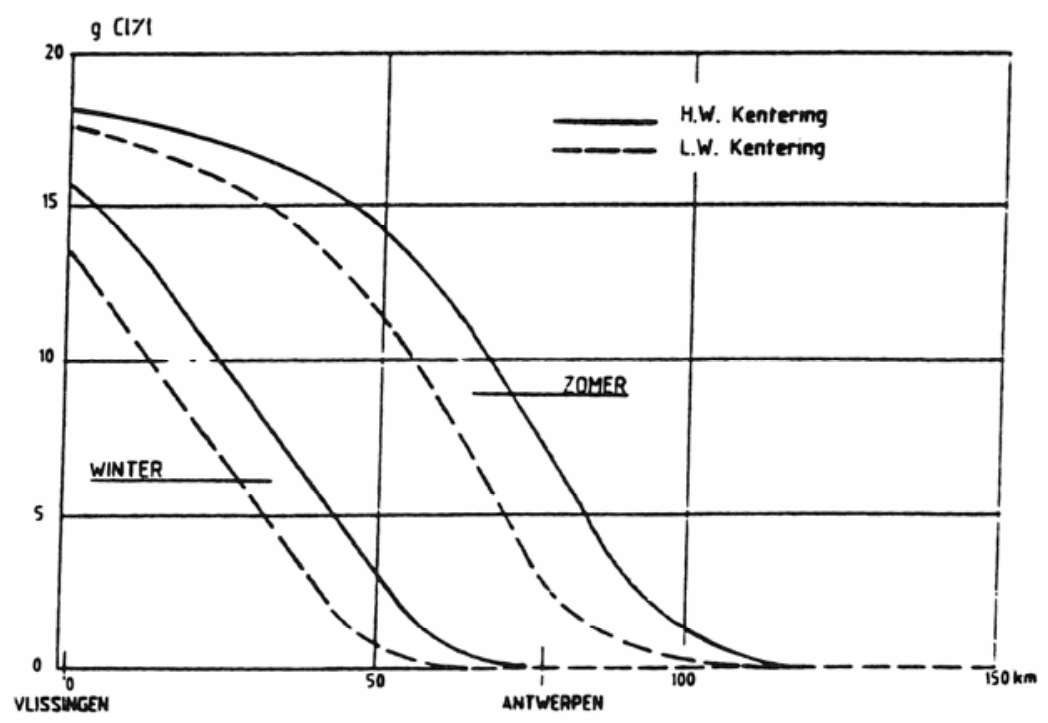

Figure 2: Longitudinal salinity distribution in the Scheldt estuary for a high and a low discharge situation. The dashed line indicates high water slack and the solid line low water slack (after Claessen, 1988). Figure from Verlaan (1998).

\subsection{Mud dynamics and properties}

Marine mud in the Scheldt estuary originates from the English Channel and the Flemish Banks. The amount of marine mud entering at the mouth is an unknown, estimated values range from 50.000 to 350.000 ton/yr (Verlaan, 1998). The amount of marine mud that is retained in the mixing zone between Rupelmonde and Vlissingen is estimated to be around $30 \%$.

Fluvial mud originates from domestic, industrial and agricultural effluent and material eroded from muddy beds. The amount of mud entering the estuary has been obtained from measurements of freshwater discharge and suspended sediment concentrations at six locations on the edge of the estuarine zone. Between 1992 and 1997 the amount of fluvial sediment varied between 75 and 250 $\mathrm{kton} / \mathrm{yr}$. In this period the amount has decreased with approximately $50 \%$. This reduction is caused by the increased treatment of domestic waste water in Flanders and Wallonia and the increased deposition upstream of Rupelmonde due to construction of a number of weirs and sluices. Most of this sediment $(80 \%)$ is retained; only a minor portion reaches the sea.

The mixing curve of suspended matter (marine and fluvial) differs from that of water (saline and fresh). Whereas the seawater fraction increases linearly with distance from the landward end of the mixing zone, the marine suspended matter increases more rapidly. The difference between seawater 
and marine suspended matter is higher near the landward than seaward side. With higher river discharges the mixing curves are shifted seaward, but the shape remains nearly the same.

The sediment concentration depends not only on the flow velocity, but also on turbulence level, regional distribution of sediment deposits, local morphology, consolidation etc. These parameters influence the deposition, resuspension and erosion rate and therefore the sediment concentration. Measurements from concentration profiles in the Scheldt estuary indicate that the maximum of depth-averaged suspended sediment concentration not always coincides with the maximum of depth-averaged current velocities. This indicates that other processes than simply resuspension and erosion (once the velocity in the water-layer exceeds a critical value) play a role. The sediment concentration often lags the flow velocity due to a combination of settling lag, threshold lag, scour lag and erosion lag. Also generation of turbulence due to velocity gradients (in vertical or longitudinal direction) may influence the development of the local concentration profile during a tidal cycle.

Deposition rates are high in entrance channels to the locks. In the Kallo lock for example 1.3 $\mathrm{cm} /$ day. Sedimentation rates of the order 0.8 to $1.7 \mathrm{~cm} / \mathrm{yr}$ on the salt marshes are derived.

Sediment floc size is a function of turbulence level, sediment concentration, organic matter, salinity, residence time, differential settling. Large flocs are regularly observed around the contact of fresh and saline water, this explains the increase in floc size in upstream direction in the Scheldt estuary (up to $120 \mu \mathrm{m}$ ). The high energy level in the middle of the estuary results in a decrease in floc size (down to $30 \mu \mathrm{m}$ ). The minimum floc size is observed at a distance between 40 and $80 \mathrm{~km}$ from the mouth.

In the Scheldt, several estuarine turbidity maxima (ETM) are observed, depending on conditions. Several mechanisms may be responsible for the creation of an ETM:

1. Estuarine circulation. The location of the ETM depends on river discharge but ebb and flood also shift the turbidity maximum up and down. A higher river discharge results in higher mass of sediment due to higher fluvial sediment supply (concentrations on the other hand do not have to become larger as the cross sectional area can be larger downstream). At high river discharge, the stratification can become so high, that the upper and lower water layer are decoupled and a large amount of fluvial sediment passes through the estuary in the upper layer and reaches the sea.

2. Tidal asymmetry (so-called tidal pumping). As the flood velocities are higher than ebb velocities more sediment is carried landwards, up to the point where the downstream river discharge becomes dominant in transporting sediment. Also the duration of slack water is longer at high water, leading to more sedimentation.

3. Flocculation

In the Scheldt, the formation of an ETM near the port of Antwerp is usually explained by a combination of estuarine circulation and tidal pumping. The fact that the ETM is located landwards of the mixing zone may imply that tidal pumping is mainly responsible for its existence. At low discharge, it is located up to $110 \mathrm{~km}$ from the mouth, whereas at high discharge it is located down to $50 \mathrm{~km}$ from the mouth (near the Belgian-Dutch border). This ETM is situated in the area of maximal energy. The residence time of sediment is longer here compared with other regions of the estuary. Concentrations in the ETM vary with a factor 2 to 10 within a tidal cycle. As the concentrations correlates well with varying tidal velocities it is expected that a major part of the suspended material is subject to deposition and resuspension within a tidal cycle whereas a minor part remains in suspension. The ETM is present during maximum current velocities and nearly absent during slack water.

During high river discharge a ETM is formed near the Dutch-Belgian border (at salinities around $5 \%$ ) suggesting that then also estuarine circulation is contributing to the formation of the ETM. An ETM is also observed near Vlissingen. According to Chen et al. (2005), this ETM is marinedominated and characterised by high wave and tide energy with SPM concentrations reaching more 
than a few hundred $\mathrm{mg} / \mathrm{l}$. Also convergence of residual currents and hydrodynamic trapping of SPM have been proposed to explain the high SPM concentration in front of the Scheldt mouth.

A river-dominated ETM, which only occurs in case of a discharge greater than $70 \mathrm{~m}^{3} / \mathrm{s}$, is present near Gent: the area of the river-dominated energy maximum is also the area of high SPM concentrations (reaching up to $300 \mathrm{mg} / \mathrm{l}$ ).

Concluding, sediment concentrations show variations on different time scales:

- flood- ebb tide

- spring- neap tide (higher during spring)

- seasonal variations depending on differences in erosion in the river (high values in winterspring and low in summer-autumn, see Figure 7.

- decades, possibly resulting from climate change.

The mud transport model should be able to reproduce these typical concentration fluctuations. Target levels are discussed in Section 3.5.

\section{Field observations and data analysis}

From the available data of the Scheldt estuary, the following data are analysed herein in some detail:

- 13h-data NAUWESB 1970 - 1981 (Figures 3 and 4)

- MWTL-data (Figures 5 - 7): mean values and seasonal dynamics

- data from Western Scheldt tunnel project on point measurement at DOW (12/1998 - 2/2002) (local water depth $-19 \mathrm{~m}$ NAP) at levels $-4,-11$ and $-17 \mathrm{~m}$ and Baalhoek (12/1998 - 11/2000) (local water depth $-9.5 \mathrm{~m} \mathrm{NAP}$ ) at levels -4.5 and $-8 \mathrm{~m}$.

- data from the Lower Sea Scheldt between Zandvliet (near the Belgian-Dutch border) and Schelle.

These are the main data sources to be used for the calibration of the mud transport model of the Scheldt estuary. For an overview of all data is referred to Van Maldegem (2002).

\subsection{NAUWESB 13h-data 1970 - 1981}

The NAUWESB dataset consists of 172 13h measurements in the Western Scheldt between Bath and Wielingen. The data have been collected in the period $1970-1981$. Figure 3 shows the locations of the monitoring locations. The 172 locations can be divided into 10 sub-areas, which show up as boxes in Figure 3.

The NAUWESB concentration measurements were made from survey vessels using sampling bottles. The measurement of one vertical took 5 to 20 minutes, starting near the bottom. The lowest measurement level was about $0.5 \mathrm{~m}$ above the bed, the highest level was about $0.5 \mathrm{~m}$ below the water surface. The current velocities were measured with an Ott propeller flow meter mounted on an ELMAR frame.

Figure 4 shows the characteristics of the vertical concentration profiles. It is evident that the western part of the Western Scheldt is more stratified than the eastern part. At EveringenTerneuzen, Honte and Wielingen the concentration at $0.5 \mathrm{~m}$ above the bed is approximately 10 times higher than the concentration near the surface. In the eastern part, the ratio $C_{\text {bed }} / C_{\text {surf }}$ is typically only 2 . Near the surface the concentration is circa $50 \mathrm{mg} / \mathrm{l}$ throughout the Western Scheldt (though with some variation). Near the bed the concentration ranges between about $100 \mathrm{mg} / \mathrm{l}$ in the eastern part and $300 \mathrm{mg} / \mathrm{l}$ in the western part. 


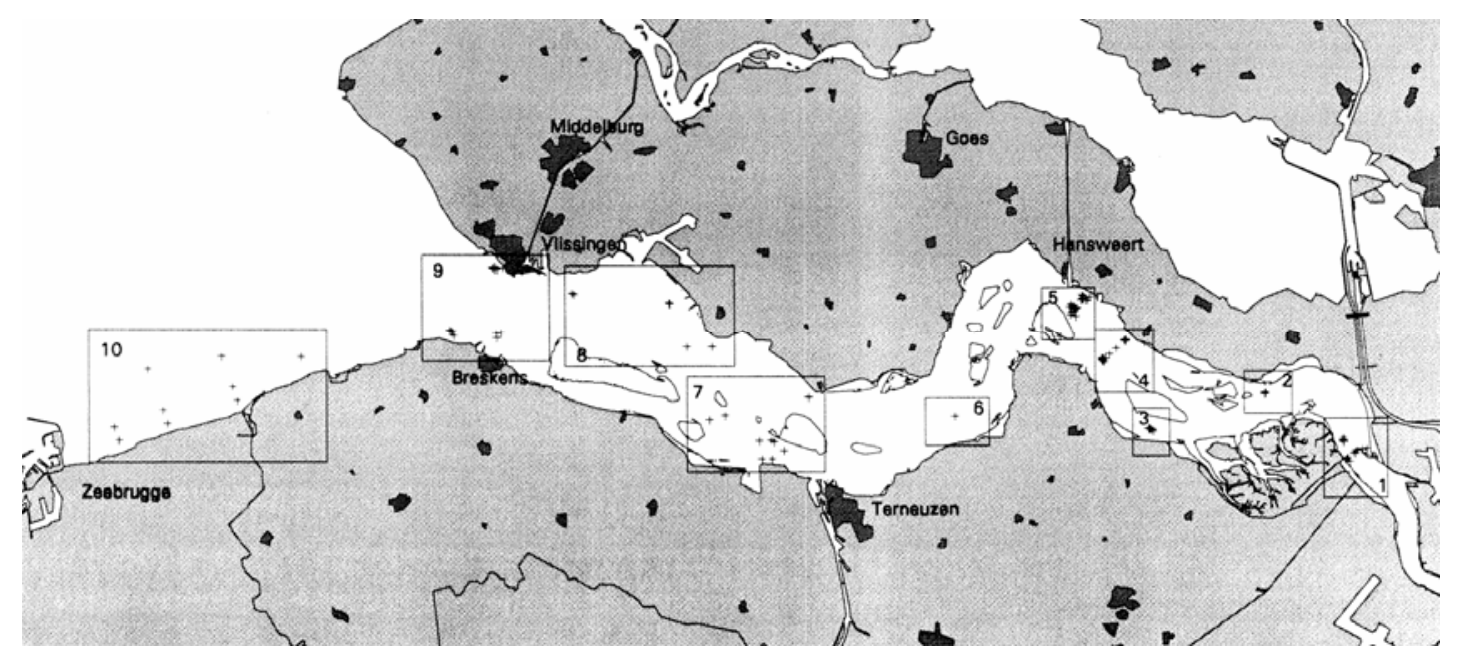

Figure 3: Locations and sub-areas with 13-hour measurements in the Western Scheldt according to file NAUWESB (1970 1981) (Mulder, 1995).

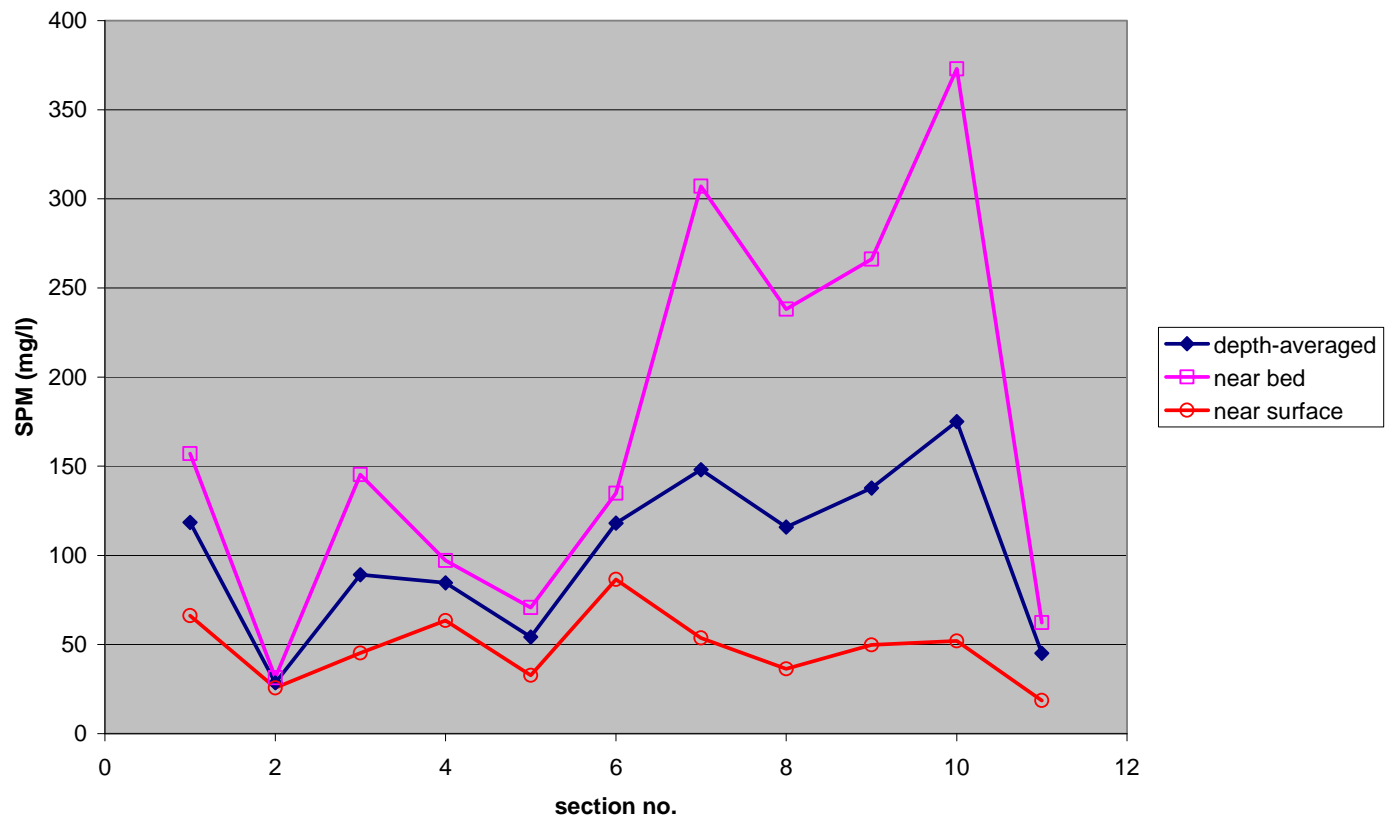

Figure 4: Tide-averaged SPM concentrations at the surface, near the bed and depth-averaged from sections 1 (Bath) towards 10 (Wielingen) (see also Fig. 3). Section 11 is the Oostgat.

\subsection{MWTL-data Western Scheldt}

The MWTL dataset is used to investigate the spatial and seasonal variations of the SPM levels in the Western Scheldt. Figure 5 shows the locations of the monitoring stations. All samples are taken at $1 \mathrm{~m}$ below the water surface at irregular intervals. Although being irregular, the sampling intervals are not random: some locations are often sampled during the same phase of the tide. The average values should therefore not be considered as representative tide-averaged concentrations.

The SPM concentrations are determined from water samples taken from the subsurface. The samples are taken at reported depths varying between 1 and $4 \mathrm{~m}$ below the surface before 1990 and at $1 \mathrm{~m}$ below the water surface after 1990. In the period $1995-1983$ the sampling time was fixed with respect to the tidal phase, from 1994 the sampling time was arbitrary. In the data series some bias towards calm period is introduced as the survey vessel operation stops for wave heights over 2 
$\mathrm{m}$. The most frequently sampled stations are sampled at a fortnightly interval. Some other stations are sampled much less frequently.

Two aspects from the MWTL data are evident:

1. The SPM concentration in the Western Scheldt increases both towards the Dutch Belgium border and towards the North Sea (Fig. 6). The latter increase may be related to the turbidity maximum near Zeebrugge. The SPM concentration off the coast of Walcheren and in the Oostgat is much lower than in the southern part of the estuary mouth. The NAUWESB dataset shows a similar concentration distribution in the estuary mouth (Fig. 4) .

2. The SPM concentration shows a clear seasonal trend: in winter the concentration is much higher than in summer (see Figs. 6-7). The seasonal variability is at least a factor 2 .

Both aspects should be reproduced by the mud transport model.

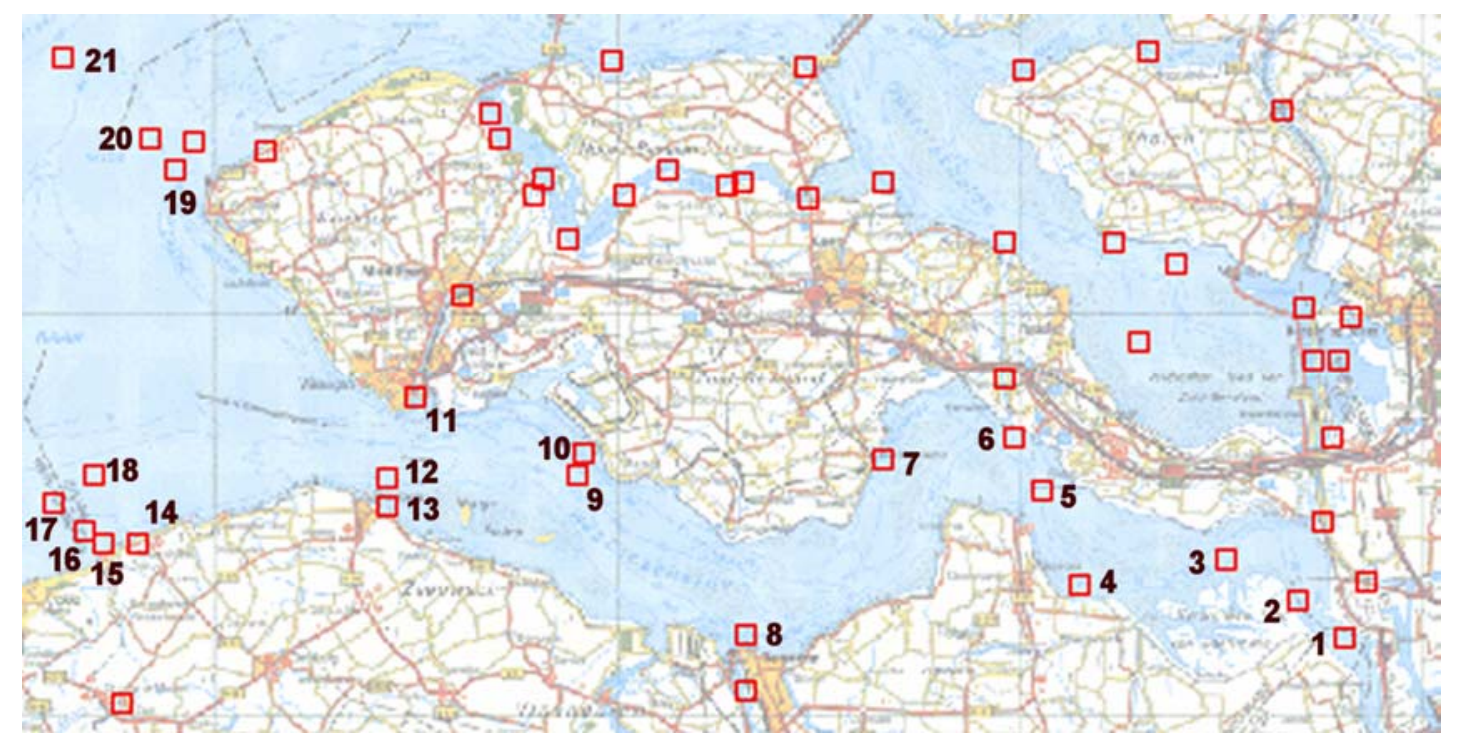

Figure 5: Locations of MWTL monitoring stations

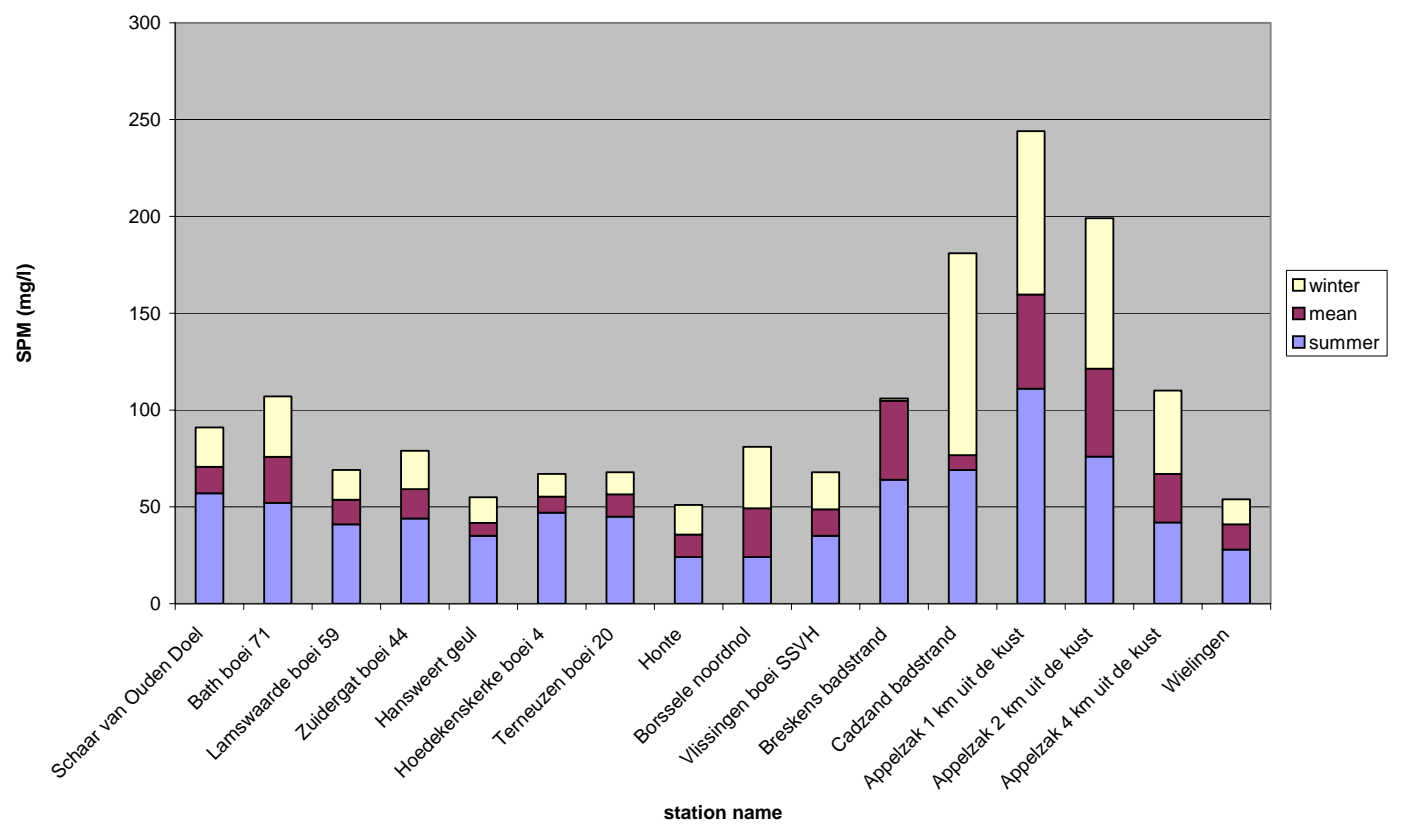

Figure 6: Year mean, winter mean and summer mean observed SP concentration at the Western Scheldt. 


\section{Terneuzen}

1982-2005

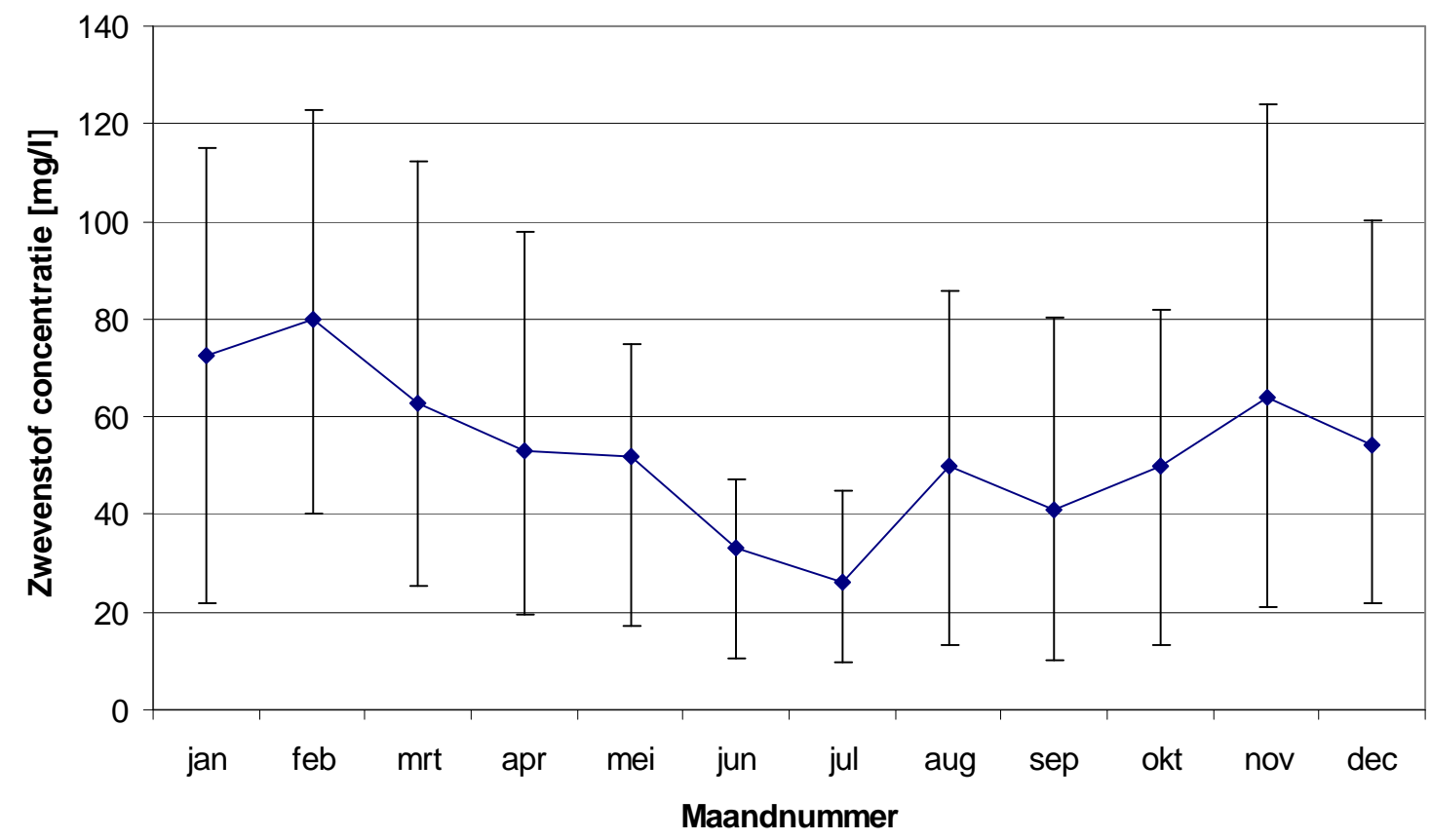

Figure 7: Seasonal concentration fluctuations at Terneuzen, period $1980-2004\left(n_{\text {obs }}=466\right)$. Monthly averaged, 10 and 90 percentile values.

\subsection{Data from Western Scheldt tunnel project at Terneuzen}

Figure 8 shows the 14-day average SPM levels at three vertical levels obtained from a measuring campaign in the framework of the Western Scheldt tunnel project. The SPM levels were determined optically with MEX3001 turbidity sensors. The calibration curves were based on water samples taken at a 4-weekly interval. Note that slurry release took place between 1 November 1999 and 31 December 2001 near the observation point at Terneuzen. Within this time window, the observed SPM concentration may be temporarily be increased with respect to the natural background concentration because of this slurry release. Two observation points were installed: one at DOW jetty (period 12/1998 - 2/2002) (local water depth -19 m NAP) at levels $-4,-11$ and $-17 \mathrm{~m}$ and another at Baalhoek (12/1998 - 11/2000) (local water depth $-9.5 \mathrm{~m} \mathrm{NAP})$ at levels -4.5 and $-8 \mathrm{~m}$.

The following conclusions may be drawn from this dataset:

- The SPM concentration is vertically quite uniform.

- The SPM fluctuations have a strong tidal component M2, M4 and S2 (12.5h tide and neapspring cycle)

- The marked seasonal fluctuation appears to be caused by a combination of freshwater discharge and wind climate (N.B. non-physical effects forcing the seasonal cycle such as biological activity are presently excluded from the model, although they may have a significant contribution. Examples of biological activity: 1. production of SPM from algal growth; 2. stabilisation of tidal flats). 


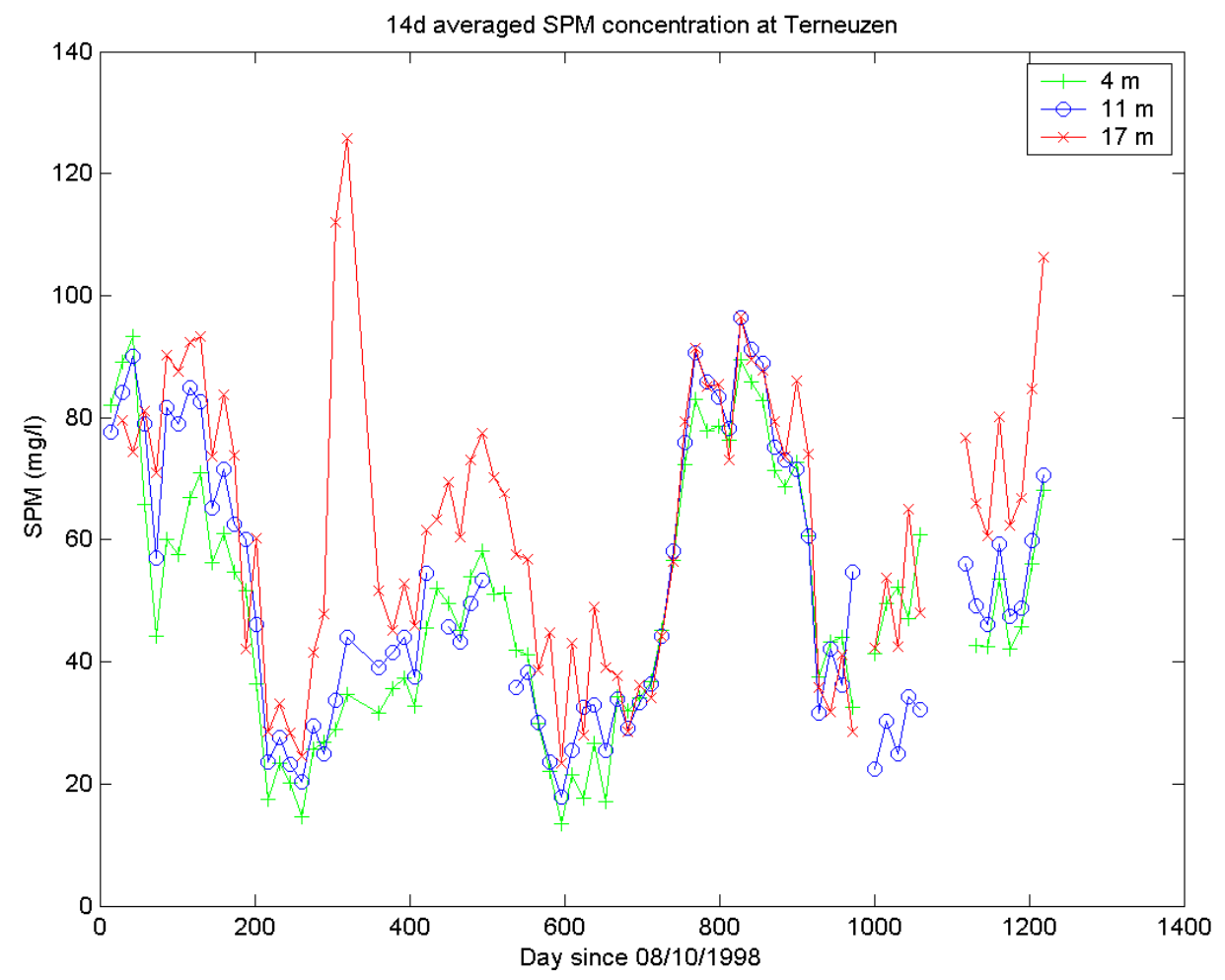

Figure 8: 14d-mean SPM concentration at Terneuzen (location DOW-jetty) at 3 vertical levels.

\subsection{Data on Lower Sea Scheldt}

Data are available both from an operational sediment data acquisition infrastructure covering the period $1999-2005$ and from a few incidental measuring campaigns, the Oosterweel campaign and the HCBS campaigns.

Based on the data from the operational acquisition infrastructure, a relationship has been established between the sediment flux and the average current velocity for the upper reaches of the estuary. The sediment flux can be estimated from SPM point measurements. This relationship is still under investigation, but it is a promising approach to estimate the fluvial sediment supply.

In the framework of a study on the Oosterweel tunnel link SPM measurements on 3 locations have been carried out. Time series on current velocity and SPM levels are available from 5 sensors on 3 locations. This dataset is similar to the dataset obtained for the Western Scheldt tunnel project at Terneuzen.

The HCBS measuring campaigns (High Concentration Benthic Suspensions) have been carried out in separate steps between February 2005 and September 2006. Amongst others, INSSEV and silt profiler measurements have been made.

The INSSEV measurements consist of an analysis of video images to determine the size and settling velocity of individual flocs. The measurements were carried out in February 2005 and were located at two positions: near the entrance of the future DGD and near Kallo sluice.

The silt profiler has been developed to measure vertical sediment concentration profiles with a high spatial and temporal resolution. Silt profile measurements were carried out near DGD on February 16 and 17, 2005, and near Kallo sluice on February 18, 2006. The measurements give a very detailed insight into the vertical concentration profile at each location. A typical feature occurring in many profiles, is the strong curvature in the concentration profile close to the bed. The 
measurements made at a number of times at a single location can be combined into a graph showing the time variation of the SMP concentration profile.

This dataset is unique in the sense that measurements were made very near to the bed, and that the design of the silt profiler allows for measurement with a very high vertical resolution (of about 1 $\mathrm{cm}$ ) and up to a very high concentration (up to $50 \mathrm{~g} / \mathrm{l}$, but this value was never reached during the present data campaign). For the benefit of the HCBS measuring campaign two additional fixed SPM monitoring points have been established in the Scheldt. The measurements will continue for one year.

\subsection{Data summary}

From the literature analysis and the system description the following key numbers are reiterated:

- Vertical tide (neap/mean/spring): 4.49/5.24/5.93 $\mathrm{m}$ at Schelle (location of maximum tidal range)

- Tidal volume: $>10^{9} \mathrm{~m}^{3}$. In the mouth the sum of ebb and flood volume $\approx 2 \times 10^{9} \mathrm{~m}^{3}$.

- Freshwater discharge (summer/mean/winter): $20 / 120 / 600 \mathrm{~m}^{3} / \mathrm{s}=5.3 \times 10^{6} \mathrm{~m}^{3}$ (mean) per tide

- Residence time freshwater: 2 - 3 months

- Average SPM concentration: $50 \mathrm{mg} / 1$

- Tidal variation SPM: factor 2 to 5

- Neap-spring variation SPM: factor 1.5 to 2

- Seasonal variation SPM: factor 2

- Vertical concentration gradients: factor 2 to 10

- Siltation: slikken: increasing down-estuary from 0.2 to $1.7 \mathrm{~cm} / \mathrm{y}$ (average $0.6 \mathrm{~cm} / \mathrm{y}$ ) towards the Belgian-Dutch border (Wartel and Van Eck, 2000), $0.8-1.7 \mathrm{~cm} / \mathrm{y}$ at Saeftinghe salt marsh; two orders of magnitude faster at harbour basins: $1.3 \mathrm{~cm} /$ day at Kallo sluice (Verlaan, 1998). Tidal marshes: $1-2 \mathrm{~cm} / \mathrm{y}$ according to Temmerman (2003). Harbour siltation: $1.2 \mathrm{MT} / \mathrm{y}$ (derived from dredging volume).

- Available mass of sediment (Van Maldegem, 2002):

o $13 \mathrm{MT}$ in the bed

o $\quad 0.1-0.4$ MT suspended

o load from sea and upstream: $0.2 \mathrm{MT} / \mathrm{y}$

o load from dumping: $1.5 \mathrm{MT} / \mathrm{y}$

\section{Model setup}

\subsection{Model requirements}

The main requirement for the mud transport model is to reproduce the observed mud distribution in the Scheldt estuary and the changes herein in space and time induced by variations of river discharge, tide, wind and waves. More in particular, the following aspects should reproduced:

1. the spatial distribution of suspended particulate matter (SPM), notably near the estuarine turbidity maximum (ETM) near Antwerp;

2. vertical SPM concentration gradients;

3. intra- and intertidal SPM concentration fluctuations, including seasonal dynamics;

4. bed composition; the spatial distribution of sandy and muddy areas;

5. the rate of siltation on intertidal flats and in harbour basins;

6. the ratio between fluvial and marine mud;

7. the total active mud mass moving around in the estuary;

8. the long-term mud balance of the estuary, including the equilibrium between harbour siltation and the release of dredged material from harbour maintenance.

The requirement that the mud model can be applied on both the short-term and long-term necessitates the simulation of the proper equilibrium bed composition. Otherwise an initial satisfactory model performance will gradually deteriorate. 


\subsection{Model grid and hydrodynamics}

The grid has a resolution that varies between $400 \mathrm{~m}$ at the northern (seaward) boundary, over $300 \mathrm{~m}$ around Zeebrugge and the Belgian coast, to $150 \mathrm{~m}$ in the Western Scheldt and up to $50 \mathrm{~m}$ in the Upper Sea Scheldt around Ghent. It has 170.000 active grid cells in a matrix of 379 to 2242 . The 3D model has 5 horizontal layers. A computation of a full year required close to one month of computer time. Sea boundary conditions are obtained from simulations with a hydrodynamic model of the southern North Sea. A uniform roughness has been applied (Manning coefficient = $0.022 \mathrm{~m}^{1 / 3}$ ). The applied simulation period is $1 / 1 / 200022 \mathrm{~h} 30$ (HW) until $3 / 4 / 200022 \mathrm{~h} 30$. For further information is referred to Van Kessel et al. (2006).

\subsection{Process formulations for mud transport}

The bed of the Scheldt estuary is represented by two layers. Conceptually, the first layer is the thin fluffy fine sediment layer deposited during slack water. At high current velocity, most or nearly all of this layer is resuspended into the water column. The critical shear stress for resuspension $\tau_{\text {critl }}$ of this layer is low and its erosion constant $M$ is high. If less than a certain mass $m_{1 \rightarrow 0}$ per unit area of fine sediment is available in layer 1, it may well be assumed that the surface coverage of the underlying bed forms is not complete. In this case, the resuspension constant $M$ will become dependent on the percentage of surface coverage. A transition between zeroth order and first order resuspension behaviour occurs. The expression for the erosion flux from layer $1 F_{\text {erol }}$ now reads:

$$
F_{\text {erol }}=\min \left(M_{0}, m M_{1}\right) \times \max \left(0,\left(\tau / \tau_{\text {crit } 1}-1\right)\right),
$$

where $M_{0}$ and $M_{1}$ are the zeroth and first order resuspension constants, respectively and $m$ the available sediment mass per unit area in layer 1 . By definition, $M_{0}=m_{1 \rightarrow 0} M_{1}$.

Conceptually, the second bed layer with user-defined thickness $d$ represents the sand bed which prevails in the Scheldt estuary. The erosion flux of fine sediment present in the pores of the sand bed is expressed as:

$$
\begin{aligned}
& D_{*}=D_{50}\left((s-1) g / v^{2}\right)^{1 / 3} \\
& F_{\text {ero } 2}=p M_{2} \rho_{\mathrm{s}}\left((s-1) g D_{50}\right)^{0.5} D_{*}^{0.3}\left(\tau / \tau_{\text {crit2 }}-1\right)^{1.5}=p M_{2}^{\prime}\left(\tau / \tau_{\text {crit } 2}-1\right)^{1.5},
\end{aligned}
$$

where $M_{2}{ }^{\prime}=333 M_{2}$ throughout the present study. The value of 333 follows from the standard values of $\rho_{\mathrm{s}}=2600 \mathrm{~kg} / \mathrm{m}^{3}, \mathrm{~s}=\rho_{\mathrm{s}} / \rho_{\mathrm{w}}=2.5, D_{50}=310^{-4} \mathrm{~m}$. The power of 1.5 appears in expression (5.2) because of the Van Rijn type of erosion function used. The erosion rate increases linearly with the mud fraction $p$.

The sedimentation flux is split into two fractions. Parameter $\alpha$ steers the sedimentation towards layers 1 and 2:

$$
F_{\text {sed } 1}=(1-\alpha) w_{s} C ; F_{\text {sed2 }}=\alpha w_{s} C .
$$

As $\alpha<<1$, the rate of sediment exchange between the water column and the first layer is much higher than the rate of exchange with the second layer. In combination with a much higher typical sediment mass per unit area in layer 2 compared with layer 1, the residence and response times of sediment in layer 2 are much longer. Whereas layer 1 responds on the tidal time scale (hours), layer 2 responds on the seasonal scale (months to years). The neap-spring tidal cycle (14 days) may influence both layers.

The formulations for layer 2 discussed above were developed on the framework of the MER sand mining study for Maasvlakte-2 (Van Ledden et al., 2006). Also the first order erosion concept was applied to layer 1 herein. The transition between first and zeroth order erosion for layer 1 is a new concept introduced in the present study. The rationale behind this transition is the much higher mud 
content of the Scheldt estuary compared with the North Sea, as the first order erosion concept becomes unrealistic for areas with a high availability of mud.

As the model consist of two mud fractions (of fluvial and marine origin), the material parameters have to be specified for both fractions. No sand transport is modelled; the sand layer (layer 2) is assumed to be passive with constant thickness $d$, but contains a variable mud fraction.

To conclude, the following parameters have to be specified:

\section{Water column:}

Settling velocity fraction $1: \quad w_{S \mathrm{~F} 1}(\mathrm{~m} / \mathrm{s})$

Settling velocity fraction 2 : $\quad w_{\mathrm{SF} 2}(\mathrm{~m} / \mathrm{s})$

Partition coefficient fraction 1: $\alpha_{\mathrm{F} 1}(-)$

Partition coefficient fraction 2: $\alpha_{\mathrm{F} 2}(-)$

\section{Layer 1:}

Critical shear stress for erosion fraction 1: $\quad \tau_{\text {crit1F1 }}(\mathrm{Pa})$

Critical shear stress for erosion fraction 2: $\quad \tau_{\text {crit1F2 }}(\mathrm{Pa})$

$1^{\text {st }}$ order resuspension parameter fraction 1: $\quad M_{1 \mathrm{~F} 1}(1 / \mathrm{s})$

$1^{\text {st }}$ order resuspension parameter fraction 2: $\quad M_{1 \mathrm{~F} 2}(1 / \mathrm{s})$

$0^{\text {th }}$ order resuspension parameter fraction 1: $\quad M_{0 \mathrm{~F} 1}\left(\mathrm{~kg} / \mathrm{m}^{2} / \mathrm{s}\right)$

$0^{\text {th }}$ order resuspension parameter fraction 2: $\quad M_{0 \mathrm{~F} 2}\left(\mathrm{~kg} / \mathrm{m}^{2} / \mathrm{s}\right)$

\section{Layer 2:}

Layer thickness: $\quad d(\mathrm{~m})$

Critical shear stress for erosion: $\tau_{\text {crit2 }}(\mathrm{Pa})$

Resuspension parameter $\quad \mathrm{M}_{2}\left(\mathrm{~kg} / \mathrm{m}^{2} / \mathrm{s}\right)$

Note that only the mud fraction $p$ may be eroded from layer 2. The sand layer will always remain in place with constant thickness $d$, as the present mud transport model is not a morphological model in which bed level changed are computed.

\subsection{Limitations}

The proposed model formulations do NOT include the following phenomena:

- fluid mud dynamics

- flocculation: constant settling velocity:

- biology-driven seasonal dynamics

- biological production of SPM from algal growth

- consolidation (strength increase in time)

- sand/mud behaviour

- sediment-water interaction (i.e. no influence of sediment on water motion)

These phenomena may be included in a later phase of the project (after 2007) if the analysis of the model performance suggests that one or more of the effects mentioned above are the key towards improvement.

\section{Model calibration}

The calibration has been carried out according to the following steps:

1. Based on field data and remote sensing, determine the proper sediment concentration boundary conditions and loads. Also the dredging and dumping activities within the model domain should be considered.

2. Use a point model in combination with the datasets from Terneuzen (with a high temporal resolution) to obtain optimal settings for the model parameters such as $w_{s}, \tau_{\text {crit }}$ and $M$. 
3. Assuming a typical spatial concentration distribution in the Scheldt, compute the location of the isolines for ${ }_{t} \int\left[M_{E}\left(\tau-\tau_{\text {crit }}\right)-w_{s} C\right] \mathrm{d} t=0$. These isolines designate the transition between sandy soil without net mud accumulation (but with thin temporary mud deposits during slack water and with a mud percentage in the sand bed in equilibrium with the mud supply and local shear stress conditions) and muddy soil with, on the long term, net accumulation of mud. Note that muddy soils subject to net long-term erosion will eventually (i.e. in equilibrium with the long-term average conditions regarding sediment supply and bed shear stress) become sandy soils.

4. Bring the magnitude of the vertical exchange in accordance with field observations by changing $\tau_{\text {crit }}$ and $M_{E}$ such that the equilibrium set under 3) does not change. Field data on net sediment accumulation (e.g. the evolution of tidal flats and dredging volumes in harbour basins) and on the suspended sediment concentration variation over the tide in shallow areas (where the sediment concentration is steered by local vertical exchange processes) are useful input to optimize vertical exchange. Some iteration between steps 2, 3 and 4 may be required.

5. The next step is to apply these parameters settings to the 3D numerical mud transport model. During this step, a further optimisation in parameter settings may be required because of the limitation of the point model, which neglects both variations in sediment supply and local horizontal concentration gradients which may show up in the SPM time signal caused by advection.

6. Two versions of the mud transport model are used: one version with a coarse grid that can be used for long-term simulations (months to years) and a second version with a fine grid for short-term simulations (days to weeks). The coarse version can supply the initial conditions for the fine version. The coarse version can be used to investigate the effects of seasonal dynamics and peaks in river discharge, whereas the fine version is meant to investigate the more local behaviour on the tidal scale (25h, preferably also $14 \mathrm{~d})$.

7. The model has been set-up with two sediment fractions: a marine fraction and a fluvial fraction. At a later stage, more fractions may be included, such as a very fine fraction with a low settling velocity. This fraction may not be so important for the sediment balance of the estuary, but may be important if the model is used as an engineering base for light climate simulations.

Having followed the procedure described above, the model performance is evaluated based on the list of desiderata. The strong and weak points of the model are determined.

\section{Results on model validation}

Tidal analysis of modelled and predicted water levels shows that the amplitude of the tidal signal is predicted well throughout the modelling domain. There is probably a $5^{\circ}$ phase lag of M2 and a $10^{\circ}$ phase lag of M4 in the boundary condition. In the current modelling set-up, the boundaries are read-in as time series out of a larger model (ZUNO) which makes phase corrections of separate harmonic components a tedious task. Upstream Antwerp the model predicts a drop in M2 and M4 amplitudes that is not represented in the measurements. This difference is considered important for possible future applications of the model in the region upstream of Antwerp (such as GOG's), and is under current investigation.

The mud transport model is sufficiently fast to compute a period of three years, which is sufficient to reach equilibrium conditions both in the water column and in the bed. Note that this period of 3 three years utilizes a hydrodynamic period of 3 month with actual wind forcing (Jan - Mar 2000), which is used 12 times in sequence. Figure 10 shows the equilibrium mud fraction in the bed, which matched the observed mud fraction (McLaren, 1994) quite well. The model shows a distinct seasonal trend, with the lower concentration in summer and the higher concentration in winter. Although the computed trend is in global agreement with the observed seasonal trend in SPM levels, based on the SPM boundary conditions as the only forcing factors. In the model, the higher winter concentration results from a higher sediment load up-estuary and a higher boundary concentration at sea. This implies that the modelled response mid-estuary shows a phase lag of 1 2 months and that the mud fraction in the bed increases together with the SPM concentration. 
The detailed description above is summarised as follows:

- Observed levels of suspended sediment concentrations at DOW-jetty between approximately 25 and $200 \mathrm{mg} / \mathrm{l}$ are adequately reproduced by the mud transport model. This is the result of the calibration by means of the settling velocity and the resuspension parameter.

- Variation of concentrations on the time scale of subsequent neap-spring tidal cycles is governed by the magnitude of the tidal forcing; greatest concentrations occur during spring tide whereas concentrations during neap tide are less. This is the result of increased erosion rates during spring tides as compared with neap tides. The model reproduces this phenomenon well although concentrations during subsequent spring and neap tides show somewhat greater differences than observed.

- During high water observed peaks in the suspended sediment concentrations may be the result of additional resuspension of very fine-grained sediment present at the shallow areas. These concentration peaks during high water are not reproduced by the model. It may require the inclusion of a very fine-grained sediment fraction and more detailed modelling of sediment dynamics at the intertidal areas.

- It seems that during spring tide the predicted erosion by the model is too pronounced at maximum ebb and flood flow. In addition, settling during slack water in the model results in concentration peaks near the bed. These peaks are absent in the available data set at DOWjetty. Both phenomena suggest that the magnitude of the vertical sediment fluxes should be reduced in the model. This can be realised by decreasing the settling velocity as well as the resuspension parameter in such a way that the average concentration level remains unchanged. However, a significant reduction of the settling velocity will result in too weak vertical concentration gradients compared to observations.

- Although the magnitude of suspended sediment concentrations and the variation on a time scale of several spring-neap tidal cycles are reproduced by the model, differences remain between observations and model results on the time scale less than one tidal cycle. This has implications for the reproduction of the magnitude as well as the direction (seaward or landward) of the tide-averaged sediment transport.

- Comparison of model results with field data has been focused on one location. In future a more spatial approach is recommended, where for instance satellite data and model output as presented in Fig. 10 is mutually compared. The computed fraction of marine mud and the computed mud percentage in bed are compared with field observations in Figs. 11 and 12, demonstrating that the mud model reproduces the observed spatial distribution of mud in the seabed reasonably well, both regarding the quantity (mud fraction) and quality (marine or fluvial). It is stressed that this distribution is not imposed by the user as initial conditions, but computed by the mud model starting with a uniform mud distribution or even an empty bed.

Figure 13 shows computed surface concentrations at four stations along the Scheldt estuary: Doel near the Dutch-Belgium border, Zuidergat, Honte and Wielingen. Observed mean levels are indicated with horizontal lines. The 10-percentile level (blue line) and 90-percentile level (dashed black line) enclose the observed range in suspended sediment concentrations. Furthermore mean summer and mean winter levels are given with green and red horizontal lines; the simulated period from January-March reflects winter conditions. At Doel the variation of suspended sediment concentrations between the 10- and 90-percentile levels is reproduced by the model. The computed mean suspended sediment concentrations are between observed mean levels for winter and summer conditions. The variation of suspended sediment concentrations at Zuidergat appears to be underestimated although the computed average concentration is between mean levels for summer and winter conditions. The variation of concentrations at Honte is too large in the model whereas at Wielingen the agreement between measurements and computed values is reasonable. In the latter case the model concentrations appear to decrease gradually.

The net sedimentation in harbours according to the model and the total volume of dumped material in the model, as based on field data, are given in Table 1. Harbour siltation amounts to $5.2 \mathrm{MT} / \mathrm{y}$, whereas sediment dumping amounts to $7.7 \mathrm{MT} / \mathrm{y}$ (number based on dumping permits). Table 1 also shows that 2.5 MT/y of mud is exported from the Western Scheldt to the North Sea. This export is 
likely to be caused by the excess dumping of dredged material in the Western Scheldt. Indeed, simulations for which a close match has been achieved between harbour siltation and dredging do show a small sediment import rather than a large export. However, equilibrium concentrations in the Western Scheldt remain far below observed SPM levels for these simulations.

According to Verlaan (1998) the amount of mud entering at the mouth of the estuary is unknown; estimated values range from 0.05 to $0.35 \mathrm{MT} / \mathrm{y}$. The net transport is the difference between a large sediment flux in ebb direction and a large sediment flux in flood direction. Assuming a characteristic suspended sediment concentration of $50 \mathrm{mg} / \mathrm{l}$ and a flood and ebb volume of $210^{9} \mathrm{~m}^{3}$ in a reach in the estuary mouth (approximately $15 \mathrm{~km}$ west of Vlissingen) the annual sediment flux in both directions is in the order of $70 \mathrm{MT} / \mathrm{y}$. If tidal asymmetry increases the total transport in ebb direction by only $10 \%$ an export of $7 \mathrm{MT} / \mathrm{y}$ follows, showing the sensitivity of the net transport to the asymmetry of the tide. Dronkers (2005), amongst others, discusses various conditions for net import or net export of fine sediment such as maximum currents during ebb and flood, the duration of high water slack versus low water slack, presence of waves etc. For specific characteristics of the bathymetry, such as intertidal area relative to total area, channel depth compared to tidal range, tidal asymmetry results in an export or import of fine sediment.
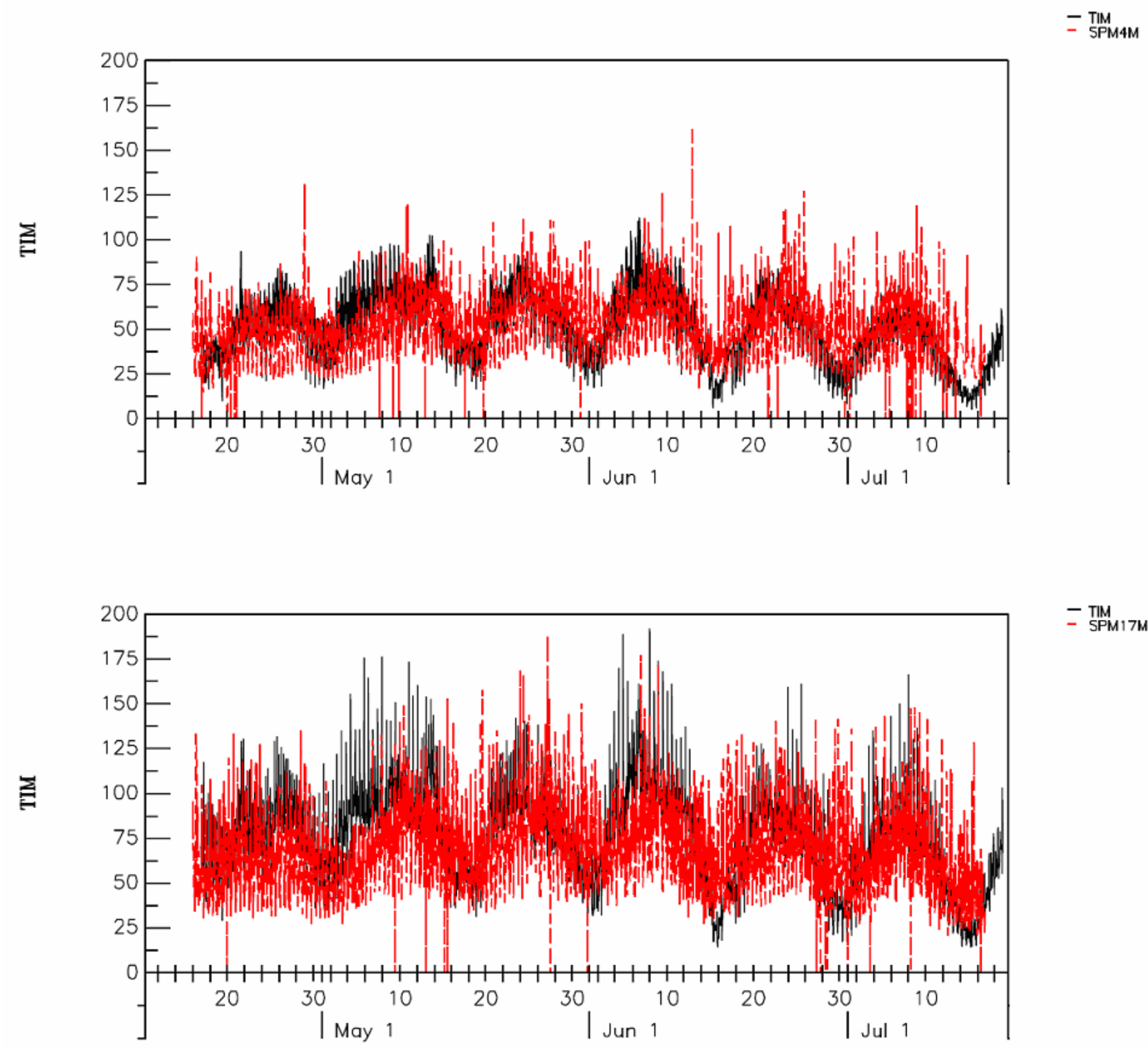

Figure 9: Computed SPM concentrations at DOW-jetty near Terneuzen for a 3-month period. Observations are included in red and model results in black. Upper panel: obs. NAP-4m, model layer 1. Lower panel: obs. NAP-17m, model layer 4 . 


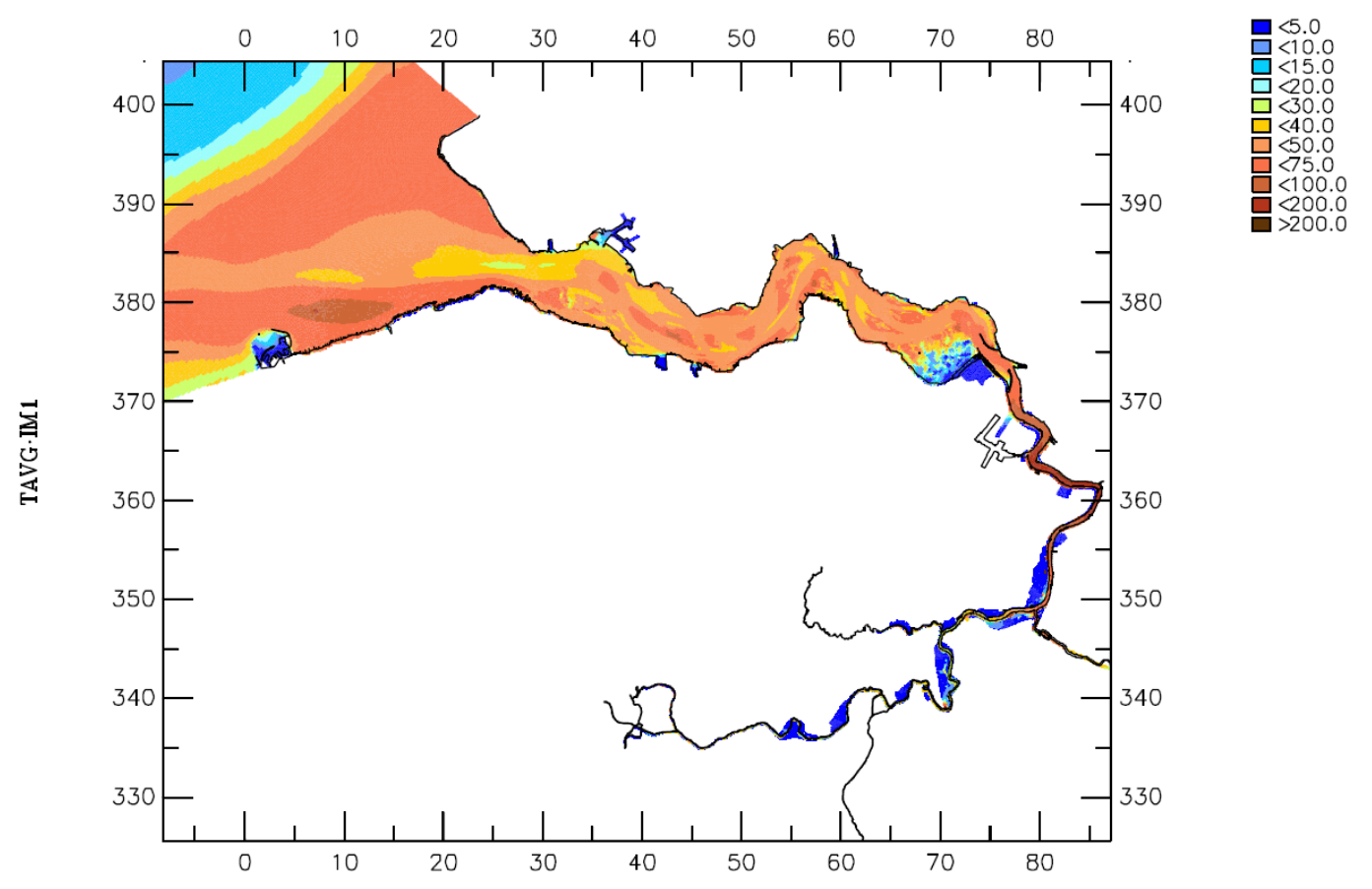

Figure 10: Computed 14-day average SPM surface concentrations (mg/l).

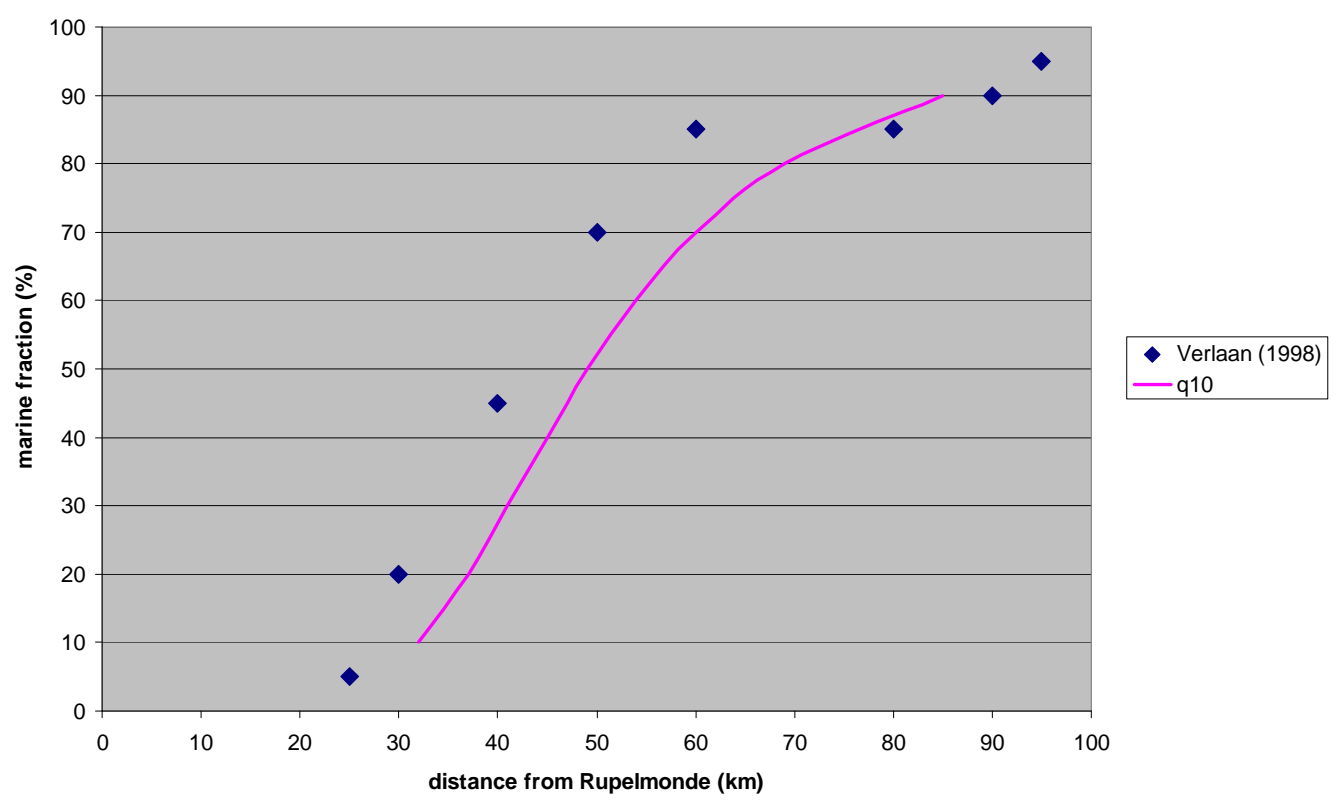

Figure 11: Observed (Verlaan, 1998) and modelled mud origin (fluvial or marine) along the estuary. 


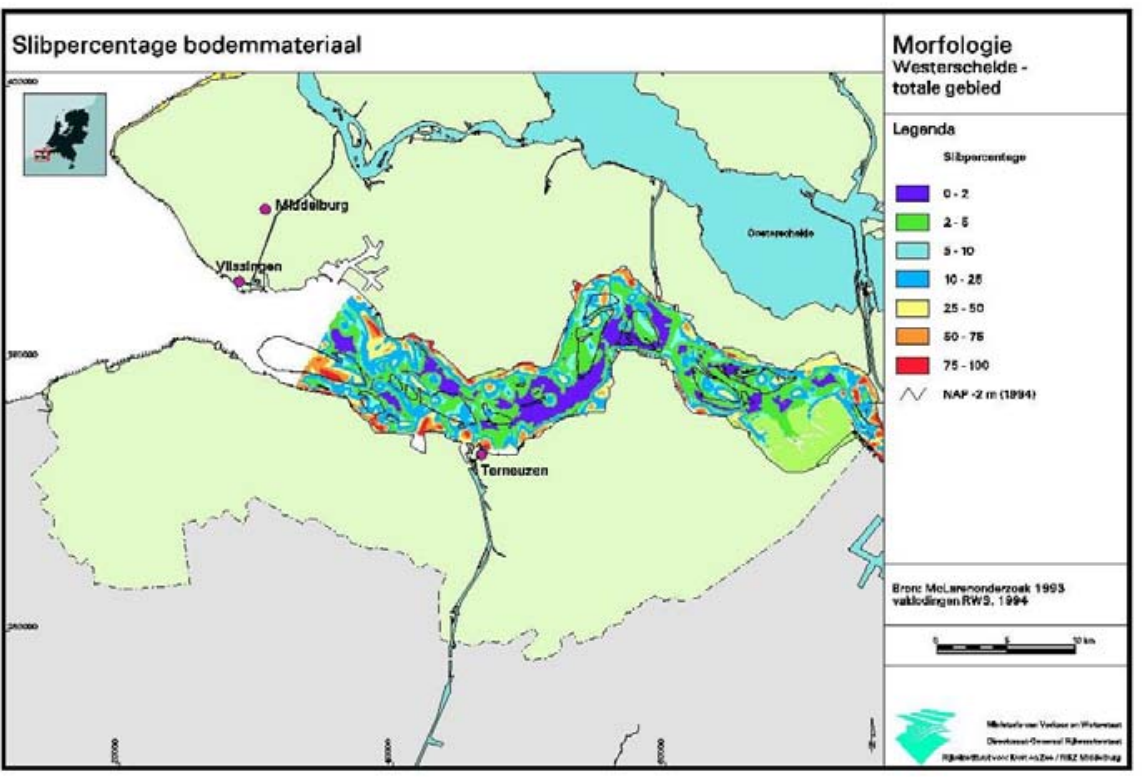

a)

b)

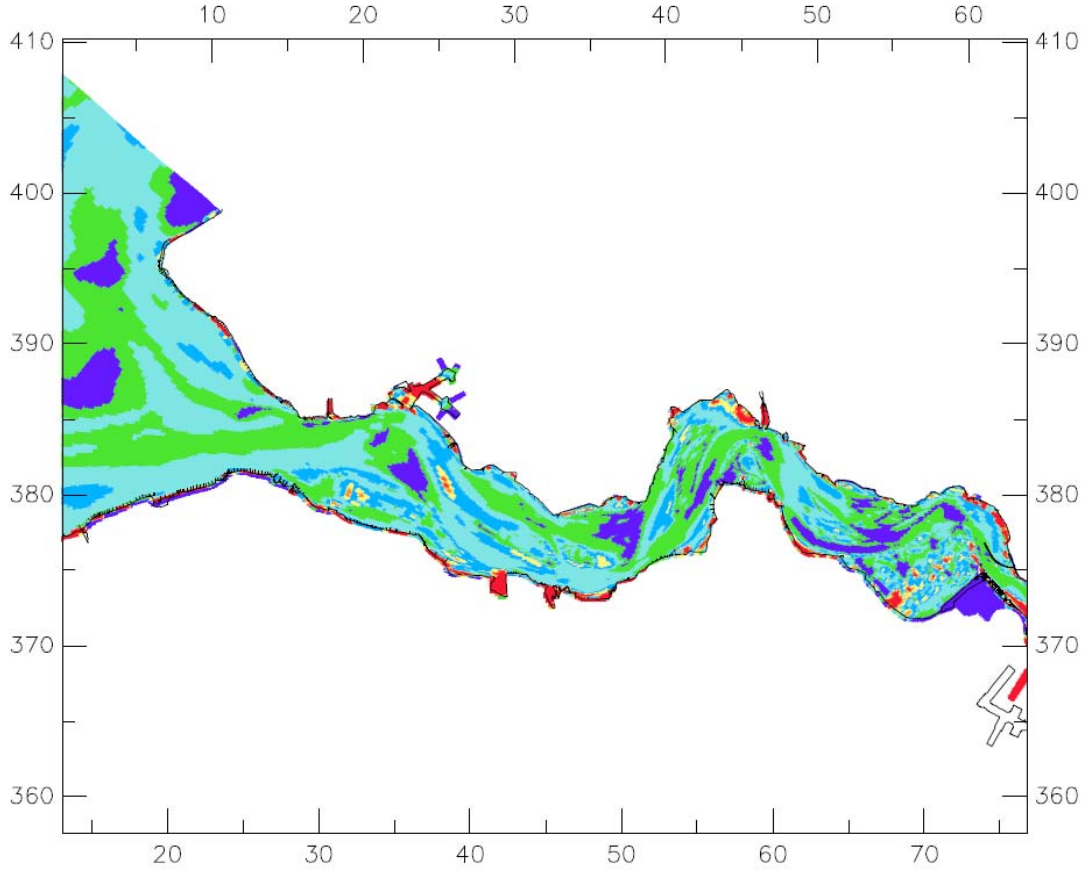

Figure 12: Observed (a) and modelled (b) mud fraction in the bed.

\begin{tabular}{|l|l|l|l|}
\hline Location & $\begin{array}{l}\text { siltation } \\
(\mathbf{k T / y )}\end{array}$ & $\begin{array}{l}\text { dumping } \\
(\mathbf{k T} / \mathbf{y})\end{array}$ & $\begin{array}{l}\text { import/export } \\
(\mathbf{k T / y )}\end{array}$ \\
\hline $\begin{array}{l}\text { Zeebrugge }+ \\
\text { Western Scheldt }\end{array}$ & 3551 & 5556 & \\
\hline Sea Scheldt & 1660 & 2120 & \\
\hline TOTAL & 5211 & 7676 & 2500 \\
\hline
\end{tabular}

Table 1: Siltation rate, dumping rate and sediment export towards the North sea for validation run (q10).

From the validation, two main conclusions can be drawn: 
1. Modelled siltation rates agree reasonably well with observed siltation rates. As the observed siltation rates vary considerably in time and also include coarser material (this has been taken into account, but the sand fraction is not always measured, but sometimes estimated), a perfect agreement between the computed and estimated siltation (based on dredged volume) would be coincidental. The computed volume is $2 / 3$ of the estimated volume, which may be considered as satisfactory.

2. The surplus of dumping with respect to siltation is $2.5 \mathrm{MT} / \mathrm{y}$, most of which is exported from the Scheldt estuary towards the North Sea. Although this residual flux is quite small compared to instantaneous sediment fluxes, it has a major influence on the overall longterm mud balance.
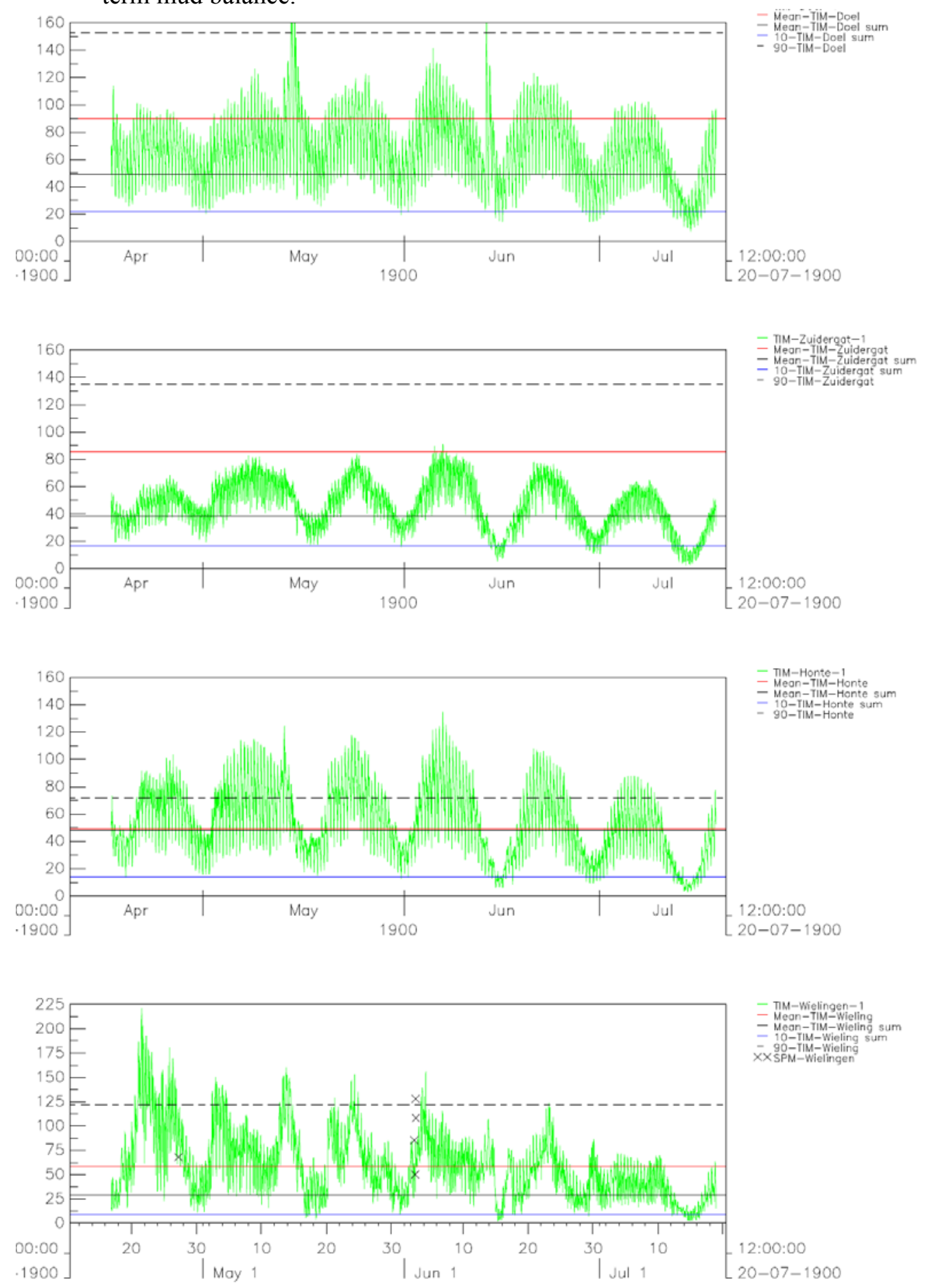

Figure 13: Computed SPM surface concentration near Doel, Zuidergat, Zuidergat and Wielingen (in green). Observed mean levels are indicated with horizontal lines. In blue: 10-percentile level; in black: mean summer level; in red: mean winter level; dashed black: 90-percentile level. 


\section{Conclusions}

The following conclusions on mud transport are drawn:

1. The SPM levels appear to be rather sensitive to the cycle of harbour siltation and dumping. Net sedimentation in the harbours is computed by the model, whereas dumping of dredged material from harbours is based on actual data. An unbalance between both quantities introduces an artificial withdrawal or discharge of sediment affecting computed suspended sediment concentrations. Therefore this aspect should be an integral part of model calibration to prevent that adjustment of model parameters are biased by the inclusion of inconsistent dumping loads due to harbour siltation.

2. Validation of the mud transport model against observed suspended sediment concentrations at DOW-jetty results in the following conclusions:

- Levels of suspended sediment concentrations at DOW-jetty between approximately 25 and $200 \mathrm{mg} / \mathrm{l}$ are adequately reproduced by the mud transport model.

- Variation of concentrations on the time scale of subsequent neap-spring tidal cycles is governed by the magnitude of the tidal forcing; greatest concentrations occur during spring tide whereas concentrations during neap tide are less. This is the result of increased erosion rates during spring tides as compared with neap tides. The model reproduces this phenomena well although the observed concentration fluctuation during a tidal cycle is somewhat greater.

3. Computed net sedimentation in the harbours along the Sea Scheldt and the Western Scheldt amounts to $2 / 3$ of actual dredge volumes. This can be considered satisfactorily given the natural variability of total dredge volumes and uncertainties in the sand content of dredged material.

4. The net export as computed by the model for the validation run amounts to $3.0 \mathrm{MT} / \mathrm{y}$. This is about one order of magnitude larger than the net import following from mud balances. Exact numbers from observations are unknown but estimates range from an import of 0.05 to $0.35 \mathrm{MT} / \mathrm{y}$. However, mud balances based on observations involve large uncertainties. Nonetheless an import from the North Sea to the Western Scheldt is expected given the observed gradual accumulation of muddy sediment on tidal flats. It is known from literature that import or export of fine sediment depends on the asymmetry of the tide. Further investigation of conditions that relate to the tidal asymmetry is needed to explain the discrepancy between observations and model results.

5. Application of a new dredging and dumping simulation methodology results in a good balance between the computed dredging volumes from the harbours and the applied dumping volumes in the estuary. However, typical concentration levels in the Scheldt estuary are significantly reduced to levels well below observed levels, down to a SPM concentration level that results in long-term mud balance with $2.5 \mathrm{MT} / \mathrm{y}$ less export from the Scheldt estuary towards the North Sea.

\section{Recommendations for future research}

The following recommendations are listed in order of suggested priority.

1. A major aspect that requires further research concerns the computed export of mud from the Western Scheldt to the North Sea. Although exact figures on the actual net sediment transport in the mouth of the estuary are not available it seems that computed values are one order of magnitude larger than estimates retrieved from mud balances. Net transport of sediment is intricately related to the asymmetry of the tide. Comparison of model results with (available) point measurements regarding flow velocity and suspended concentration of mud during a tidal cycle is recommended, to study in detail processes associated with tidal asymmetry and their effect on net sediment transport. 
2. Simulations for longer periods (at least one year) are recommended to investigate the model behaviour on the long term, i.e. including seasonal fluctuations and its effect on computed net sediment transport from or to the North Sea. Also the present 3 month period can be analysed further, e.g. by analyzing the weekly and monthly variability of the residual sediment flux.

3. Further validation of the model by means of point measurements, as recommended above, should be combined with the use of satellite images of the Scheldt estuary to allow for a more spatial comparison between observed and computed suspended sediment concentrations.

4. The model can be made operational for turbidity modelling by inclusion of appropriate routines on light extinction thus broadening the scope of the model for application on ecological management issues. This may also require in addition of a very fine fraction. Such extension facilitates the application of the model for ecological modelling.

5. A number of fundamental processes on mud dynamics have not been included in the mud transport model. This holds for the settling velocity of mud flocs which is assumed to be constant in time but in reality depends on several factors such as turbulence, suspended sediment concentration, water and sediment properties. Furthermore, the sediment dynamics in the Scheldt estuary is also governed by the transport of sand. Interaction between the non-cohesive sand and cohesive mud, especially in the bed, is not yet accounted for by the present model. It implicitly requires the modelling of the consolidation process including effects on bed shear strength.

\section{References}

Chen, M.S., S. Wartel, B. van Eck and D. van Maldegem (2005). Suspended matter in the Scheldt estuary. Hydrobiologia 540, pp. 79-104.

Claessens, J. (1988). Het hydraulische regime van de Schelde, Water 43, pp. 163-169 (in Dutch).

Dronkers, Job (2005). Dynamics of coastal systems. Advanced Series on Ocean Engineering Volume 25. World Scientific. ISBN 981-256-207-9.

Fettweis, M., M. Sas, J. Monbaliu (1998). Seasonal, neap-spring and tidal variation of cohesive sediment concentration in the Scheldt Estuary, Belgium. Estuarine, Coastal and Shelf Science $47,21-36$.

Kessel, T. van, J. Vanlede, A. Bruens (2006). Development of a mud transport model for the Scheldt estuary in the framework of LTV. WL | Delft Hydraulics report Z4210, Delft, The Netherlands.

Maldegem D. van (2002). Overzicht gegevens voor LTV-slibmodel Schelde-estuarium. Werkdocument RIKZ/AB/2004.821x. RIKZ.

McLaren (1994). Sediment transport in the Western Scheldt between Baarland and Rupelmonde. Report prepared for the Antwerp Harbour Authorities.

Mulder, 1995

Nihoul, J.C.J.F., F. Ronday, J.J. Peters, A. Sterling (1978). Hydrodynamics of the Scheldt estuary. In: J.C.J.F. Nihoul (ed.), Hydrodynamics of Estuaries and Fjords, Elsevier, Amsterdam, pp. 2753.

Peters, (1975). Les mechanismes de mélange des eaux dans l'estuaire de l'Escaut. Tijdschrift der Openbare Werken van België 2, pp. 101-119.

Temmerman, S. (2003). Sedimentation on tidal marshes in the Scheldt estuary. Ph.D. thesis Katholieke Universiteit Leuven, Belgium.

Toorman, E. (1997) Containerdok West. Hydraulisch en sedimentologisch onderzoek. Erosiegevoeligheid van de bodemsedimenten. Laboratoriumproeven. Rapport KULHYD/ET97.3

Van Ledden et al., 2006. Impact sand extraction Maasvlakte 2. Date 9 August 2006 Project name Maasvlakte 2 Project number 9P7008.O9 Client Port of Rotterdam

Verlaan, P.A.J. (1998). Mixing of marine and fluvial particles in the Scheldt estuary. Ph.D. thesis Delft University of Technoloy, The Netherlands

Wartel, S. and G.T.M. van Eck (2000). Mud budget of the Scheldt estuary. Koninklijk Belgisch Instituut voor Natuurwetenschappen, Brussels, Belgium (in Dutch). 